\title{
Kinetic Analysis of the Effect of Tetraethylammonium on Neuromuscular Transmission in the Frog
}

\author{
Takashi MaEno, Koh-ichi Enomoto, and Mitsuyuki ICHINOSE \\ Department of Physiology, Shimane Medical University, \\ Izumo, Shimane, 693 Japan
}

\begin{abstract}
The facilitatory action of tetraethylammonium (TEA) on endplate potentials (EPPs) and its depression by streptomycin (SM) were analyzed by recording EPPs from curarized frog muscles using conventional microelectrode techniques. The fractional release of transmitter was estimated from the early tetanic rundown of EPP during short train stimuli. To explain the marked facilitatory effect of TEA on the fractional release and the antagonistic interaction of SM thereupon, it was postulated that to increase the evoked transmitter release, two molecules of TEA react with two sites in a still unidentified Casensitive component $X$ of the transmitter-releasing mechanism. SM depresses the evoked transmitter release by competing with TEA for the occupancy of one of the two TEA sites. The equations derived from the present assumptions agreed reasonably well with the experimental results.
\end{abstract}

Key Words: endplate potential, neuromuscular transmission, synapse, tetraethylammonium, transmitter release.

Tetraethylammonium (TEA) is known to have two distinct actions on neuromuscular transmission in addition to its well-known blockade of $\mathrm{K}$ channels in the excitable membrane. Postsynaptically, TEA interacts with the endplate acetylcholine $(\mathrm{ACh})$ receptor-channel complex to depress the conductance change produced by ACh (KoKetsu, 1958; PARSONS, 1969; Adler et al., 1979). Presynaptically, TEA increases the number of ACh quanta released by activity in the nerve terminal (KoKetsu, 1958; Stovner, 1958; Collier and ExLey, 1963; Volle and BRANiSTEANU, 1976; KATZ and Miledi, 1979). Since TEA prolongs the duration of the presynaptic nerve action potential (KOKETSU, 1958; KuSANO et al., 1967) by blocking the $\mathrm{K}$ channels (HILLE, 1967), its effect has been attributed to an increase in the $\mathrm{Ca}$ influx associated with the action potential in the nerve terminal. A linear relationship between $\mathrm{Ca}$ current and postsynaptic potential has been demonstrated by LLINÁs et al. $(1976,1981)$.

Received for publication March 23, 1982

前野 巍, 榎本浩一, 一/瀬充行 
While studying the pharmacological interaction of 4-aminopyridine (4AP) and streptomycin (SM), we found that diamino compounds with a hexagonal skeleton modify transmitter release presumably by reacting with a binding site on the Ca-sensitive release component $\mathrm{X}$ in the nerve terminal membrane (MAENO et al., 1981). To elucidate the sequence of events between activation of this release component $\mathrm{X}$ and the evoked release of $\mathrm{ACh}$, it is first necessary to identify and characterize the molecules which react with $X$. The purpose of the present experiments was to investigate whether TEA also exerts the well-known facilitatory presynaptic action through its combination with the above binding site present on the release component X. Part of the data has already been published in a preliminary form (MAENo et al., 1982).

\section{MATERIALS AND METHODS}

The materials used were $d$-tubocurarine (dTC)-treated sciatic nerve-sartorius muscle preparations of the Japanese frog, Rana nigromaculata. The experimental procedures for recording the endplate potential (EPP) and calculation of the fractional release $(P)$ in the present investigation were basically identical to those described previously (MAENo et al., 1981). To avoid some undesirable sideeffects due to prolongation of the nerve terminal action potential by TEA, the interval between stimuli in a triple pulse stimulation was mostly set to $0.2 \mathrm{sec}$. The Ringer solution consisted of $115 \mathrm{mM} \mathrm{NaCl}, 2.5 \mathrm{mM} \mathrm{KCl}, 0.9$ to $10 \mathrm{mM} \mathrm{CaCl}_{2}$ as indicated, and $5 \mathrm{~mm}$ tris(hydroxymethyl)aminomethane. The $\mathrm{pH}$ of the solutions was adjusted to 7.2-7.3.

In experiments with focal depolarization of the nerve terminal in tetrodotoxin (TTX)-treated muscles, three supramaximal stimulating current pulses of $1.1 \mathrm{msec}$ duration were applied at intervals of $0.2 \mathrm{sec}$ to the nerve via the glass capillary suction electrode located as close as possible to an endplate. The Ringer solutions contained $1 \mu \mathrm{M}$ TTX, $0.9 \mathrm{~mm} \mathrm{Ca}$, and an adequate amount of dTC. Drugs used were streptomycin sulfate (Meiji), tetraethylammonium chloride (Eastman), tetrodotoxin crystalline $3 X$ (Sankyo) and $d$-tubocurarine chloride (Wako). Because of the humidity of the atmosphere, the concentration of TEA might be somewhat overestimated.

As has already been pointed out by several investigators (KoKETSU, 1958; Volle and BRANisTeANU, 1976; Illes and TheslefF, 1978) that TEA augments in a dose-dependent manner the amplitude of the EPP. Consequently, the concentration of dTC required to block neuromuscular transmission had to be increased with $1 \mathrm{~mm}$ TEA. However, because of the curarizing effect of TEA (KoKetsu, 1958; PARSONS, 1969; KATZ and Miledi, 1979), the concentration of dTC was not increased further at higher concentrations of TEA. 


\section{RESULTS}

\section{General properties of the enhanced evoked release with TEA}

TEA augmented, in a dose-dependent manner, the rate of early tetranic rundown of the EPP elicited with short pulse trains of stimuli (Fig. 1) from which the fractional release of transmitter $(P)$ was estimated. In the previous paper on 4AP (MAENo et al., 1981), we reported that the relation between the apparent fractional release $\left(P_{t}\right)$ and the stimulus interval $(t)$ consisted of two exponential components, and that the value of $P_{t}$ when $t$ is about $0.1 \mathrm{sec}$ was almost equivalent to $P$, the value of $P_{t}$ being anticipated at $t=0$. This holds also for the TEAtreated muscles, as presented in Fig. 2. However, the initial phase of the $P_{t}-t$
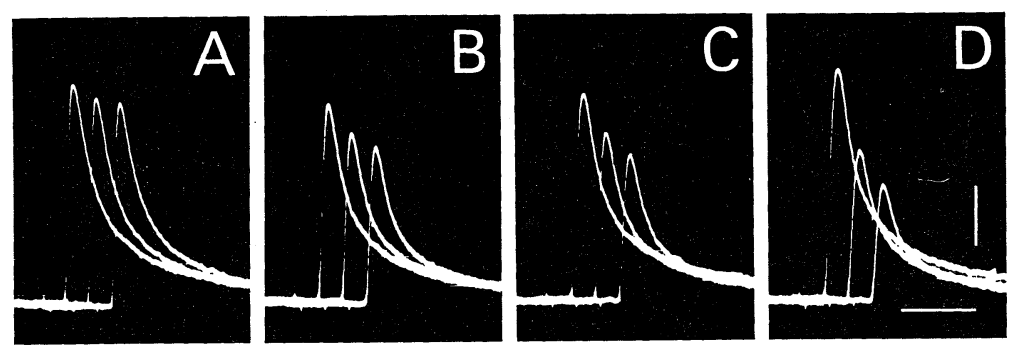

Fig. 1. Effect of TEA on the tetanic rundown of the EPP. The EPPs elicited with triple pulse stimulation of $0.1 \mathrm{sec}$ interval were recorded on moving film. The concentrations of TEA and dTC were, from A to D, $0 \mathrm{~mm}$ and $4.3 \mu \mathrm{M}, 0.2 \mathrm{~mm}$ and $11 \mu \mathrm{M}, 0.5 \mathrm{~mm}$ and $17 \mu \mathrm{M}$, and $1.0 \mathrm{~mm}$ and $20 \mu \mathrm{M}$, respectively. The external Ca concentration was adjusted to $2.5 \mathrm{~mm}$. Time scale, $5 \mathrm{msec}$; voltage calibration, $2 \mathrm{mV}$.

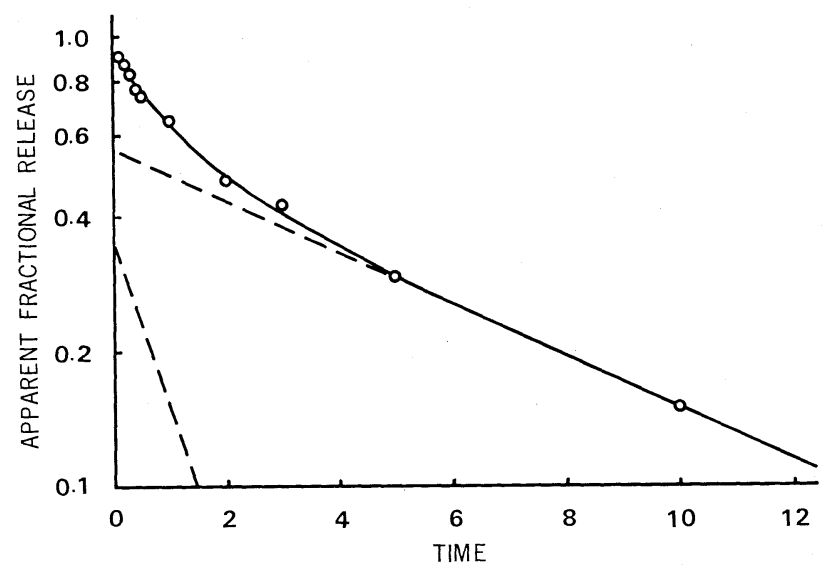

Fig. 2. The relationship between the apparent fractional release $\left(P_{t}\right)$ and the interval of stimulation $(t)$. Abscissa, $t$ in sec; ordinate, $P_{t}$ on logarithmic scale. The Ringer solution contained $5 \mathrm{~mm}$ TEA, $2.5 \mathrm{mM} \mathrm{Ca}$, and 17-23 $\mu \mathrm{M}$ dTC. Each circle represents

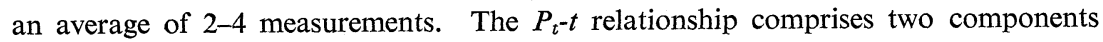
shown by the broken lines. 
relation in the presence of TEA was less prominent than the case with 4AP. The time constant of the late phase $(7.6 \mathrm{sec})$ agreed with those reported previously on curarized preparations (TAKEUCHI, 1958; OTSUKA et al., 1962; Illes and THESLEFF, 1978).

KOKETSU (1958) reported that $2 \mathrm{~mm}$ or more TEA sometimes elicited repetitive firing in response to a single nerve stimulus. This was confirmed in the present study with normal $(2.5 \mathrm{~mm})$ and low $(0.9 \mathrm{~mm})$ Ca-Ringers. Under these conditions, the amplitude of the EPP generated with the second stimulus in a train was diminished excessively due to the additional release of the available transmitter quanta by preceding repetitive terminal activity triggered by the first stimulus; this resulted in an overestimation of $P$. This was corrected as described in the previous paper (MAENo et al., 1981). In a few instances in which the EPP in response to the second stimulus was smaller than the EPP elicited by the third stimulus of the train, $P$ was calculated from the ratio of amplitudes of the third and first EPPs. In $2 \mathrm{mM}$ TEA, the repetitive nerve terminal activity was most apparent 5-10 min after replacement with TEA Ringer, but it tended to subside gradually with time. However, the repetitive electrical activity at the nerve terminal was so prominent in $10 \mathrm{~mm}$ TEA that the measurement of $P$ was quite inadequate. On the other hand, in $10 \mathrm{~mm}$ Ca-Ringer the repetitive nerve terminal activity was not observed at any concentration of TEA tested.

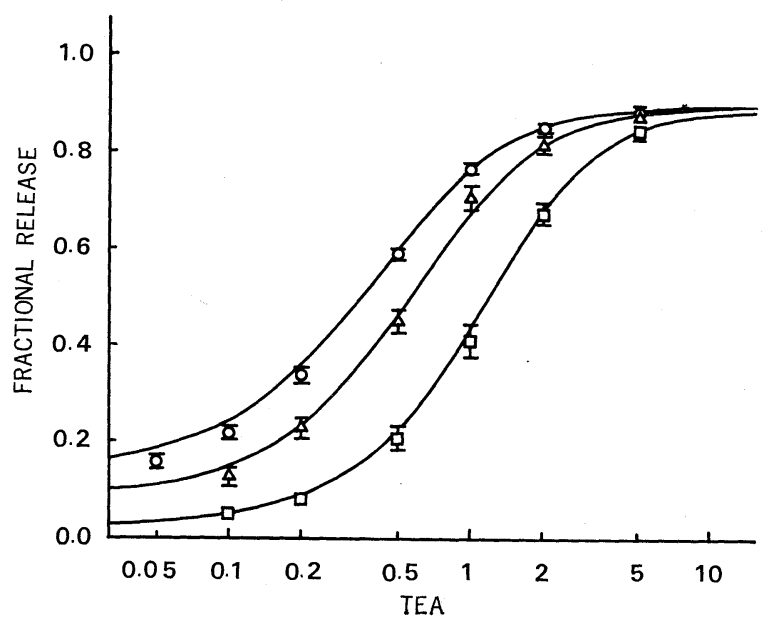

Fig. 3. Effect of $\mathrm{Ca}$ on the dose-release relation of TEA. Abscissa, the concentration of TEA in $\mathrm{mm}$ on a logarithmic scale; ordinate, the fractional release. The concentration of Ca was $0.9,2.5$, and $10 \mathrm{~mm}$ for squares, triangles, and circles, respectively. The theoretical dose-release curves of TEA were calculated from Eq. (5) with the following fixed parameters; i.e., $[\mathrm{D}]=0 \mathrm{mM}, K_{\mathrm{A}}=0.50 \mathrm{mM}, K_{\mathrm{Ca}}=0.55 \mathrm{mM}, P_{\mathrm{A}}=0.90, P_{\mathrm{Ca}_{\mathrm{a}}}=0.15$, and $\alpha=8.0$. The vertical bar shows the standard error of the mean (S.E.). The data are averages on $17(0.9 \mathrm{~mm} \mathrm{Ca}), 21(2.5 \mathrm{~mm} \mathrm{Ca})$, and $27(10 \mathrm{~mm} \mathrm{Ca})$ muscles. 

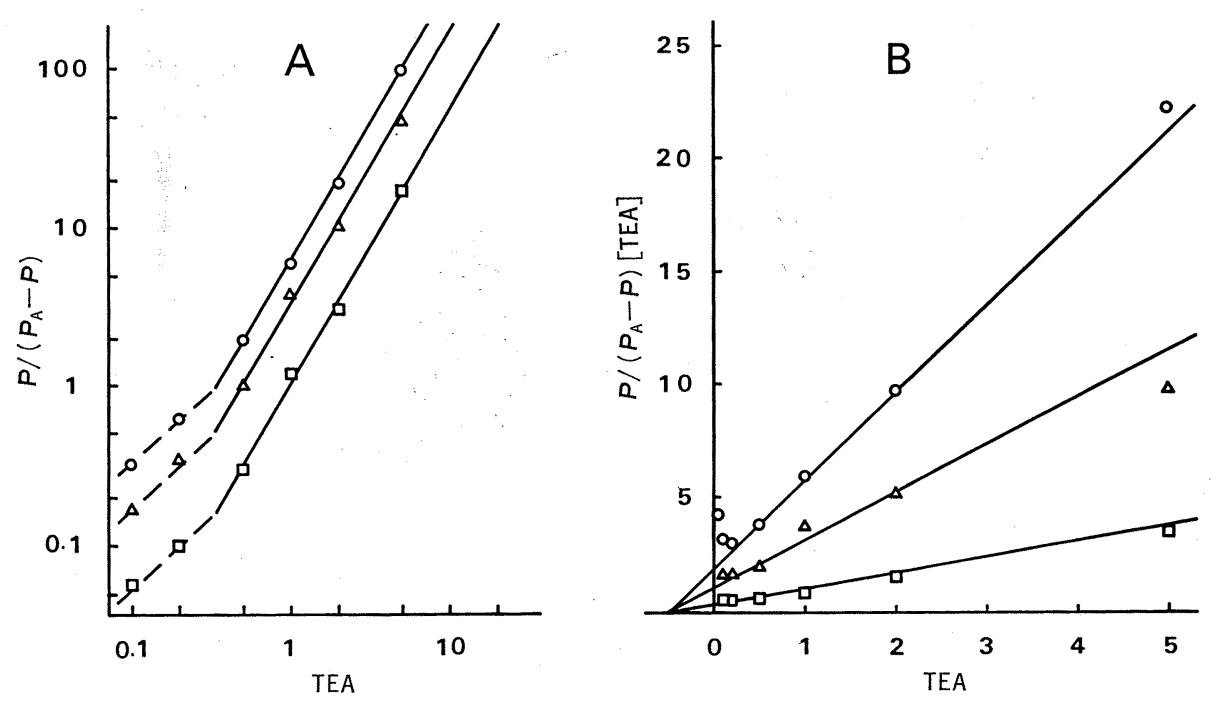

Fig. 4. A: Hill plot of the data given in Fig. 3. Abscissa, the concentration of TEA in $\mathrm{mm}$ on a logarithmic scale; ordinate, $P /\left(P_{A}-P\right)$ on a logarithmic scale. The same symbols were used as in Fig. 3. The fitted solid lines were calculated from Eq. (3) with the following parameters $\left(K_{\mathrm{A}}^{*}=0.30 \mathrm{mM}, K_{\mathrm{Ca}}=0.60 \mathrm{mM}, P_{\mathrm{A}}=0.90\right.$, and $\left.n=1.72\right)$. The Hill coefficient for the broken lines was taken to be 0.91. B: A linear relation between $P /\left(P_{A}-P\right)$ [TEA] (ordinate in $1 / \mathrm{mm}$ ) and [TEA] (abscissa in mM) found in the absence of SM by a replot of the data presented in Fig. 3. The symbols are identical with those of Fig. 3. Fitted straight lines were obtained from Eq. (7') adopting the following fixed parameters; $K_{\mathrm{A}}=0.50 \mathrm{mM}, K_{\mathrm{Ca}_{\mathrm{a}}}=0.50 \mathrm{mM}, P_{\mathrm{A}}=0.90$, and $P_{\mathrm{Ca}}=0.15$. Note that the extrapolation of the straight lines all converge to a single point on $X$-axis where $[\mathrm{TEA}]=-K_{\mathrm{A}}$.

\section{Power relationship between $P$ and TEA concentration}

As shown in Fig. 3, TEA augmented $P$ in a dose-dependent manner. However, a double reciprocal plot of these data did not yield a linear relation. This suggested that the interaction of TEA with the release process might not be a simple first order reaction as was the case with 4AP. Accordingly, we hypothesized as a first approximation that to enhance the evoked release of transmitter, $n$ molecules of TEA are required to combine with the Ca-bound release component $\mathrm{X}\left(\mathrm{Ca}_{4} \mathrm{X}\right)$ and form $\mathrm{TEA}_{n} \cdot \mathrm{Ca}_{4} \mathrm{X}$, and that $P$ in the presence of TEA is proportional to the sum of the two forms of release (MAENo et al., 1982). Namely;

$$
\begin{gathered}
4 \mathrm{Ca}+\mathrm{X} \stackrel{K_{\mathrm{Ca}}}{\rightleftharpoons} \mathrm{Ca}_{4} \mathrm{X} \stackrel{P_{\mathrm{Ca}}}{\rightleftharpoons} \text { normal evoked release, } \\
n \mathrm{TEA}+\mathrm{Ca}_{4} \mathrm{X} \stackrel{K_{\mathrm{A}}^{*}}{\rightleftharpoons} \mathrm{TEA}_{n} \cdot \mathrm{Ca}_{4} \mathrm{X} \stackrel{P_{\mathrm{A}}}{\rightleftharpoons} \text { enhanced evoked release, } \\
P=P_{\mathrm{Ca}}\left[\mathrm{Ca}_{4} \mathrm{X}\right] /[\mathrm{X}]_{\mathrm{T}}+P_{\mathrm{A}}\left[\mathrm{TEA}_{n} \cdot \mathrm{Ca}_{4} \mathrm{X}\right] /[\mathrm{X}]_{\mathrm{T}},
\end{gathered}
$$

Vol. 32, No. 5, 1982 
where $K_{\mathrm{Ca}}$ and $K_{\mathrm{A}}^{*}$ are the dissociation constants of $\mathrm{Ca}$ and TEA, respectively, $P_{\mathrm{Ca}}$ and $P_{\mathrm{A}}$ are the respective release parameters, and $[\mathrm{X}]_{\mathrm{T}}$ is the total amount of $\mathrm{X}$. Thus, $P$ can be predicted from the following equation;

$$
P=\left\{P_{\mathrm{Ca}}+P_{\mathrm{A}}\left([\mathrm{TEA}] / K_{\mathrm{A}}^{*}\right)^{n}\right\} /\left\{\left(1+K_{\mathrm{Ca}} /[\mathrm{Ca}]\right)^{4}+\left([\mathrm{TEA}] / K_{\mathrm{A}}^{*}\right)^{n}\right\},
$$

where $[\mathrm{Ca}]$ and [TEA] are the concentrations of $\mathrm{Ca}$ and TEA, respectively. When $P_{\mathrm{Ca}}$ is negligible ([TEA] $>0.5 \mathrm{mM}$ ), modification of Eq. (2) yields;

$$
P /\left(P_{\mathrm{A}}-P\right)=[\mathrm{TEA}]^{n} / K_{\mathrm{A}}^{* n}\left(1+K_{\mathrm{Ca}} /[\mathrm{Ca}]\right)^{4} .
$$

Note that $K_{\mathrm{A}}^{*}$ in Eqs. (2) and (3) is not identical with the dissociation constant of TEA $\left(K_{\mathrm{A}}\right)$ in Eqs. (5)-(7)' described in Discussion.

Consequently, Eq. (3) predicts a linear $\log \left\{P /\left(P_{A}-P\right)\right\}$ versus $\log$ [TEA] relation as presented by solid lines in Fig. 4A. The slope of this linear relationship was 1.6-1.7 and was unaffected by the presence of SM. This suggests that a bimolecular reaction might be involved in the action of TEA. However, the $\log \left\{P /\left(P_{A}-P\right)\right\}$ versus $\log [$ TEA] relation leveled off below $0.33 \mathrm{~mm}$ as shown by broken lines in Fig. 4A. The value of the apparent Hill coefficient for this region (0.91) was close to the coefficient of the power relationship between quantal content and TEA below $0.1 \mathrm{~mm}$ (0.81) reported by Volle and BRANISTEANU (1976).

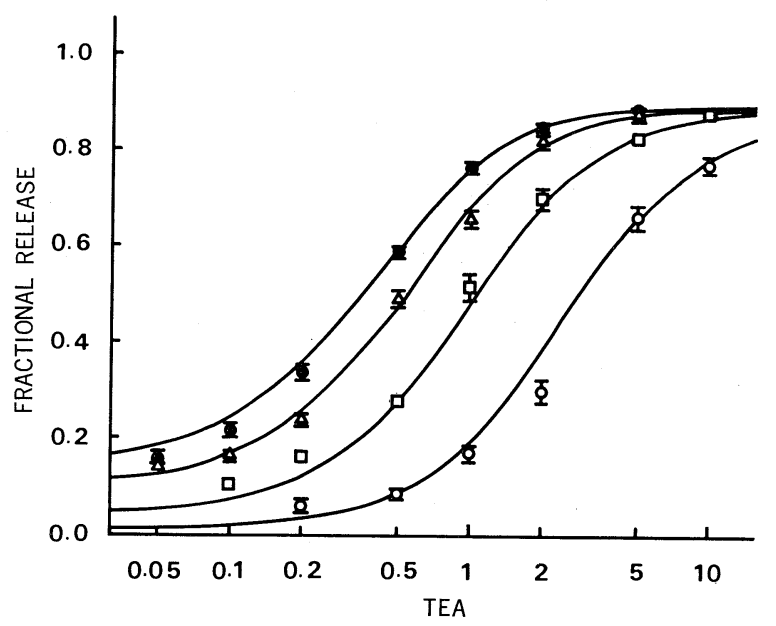

Fig. 5. Effect of SM on the dose-release relationship of TEA. Abscissa, the concentration of TEA in mM on a logarithmic scale; ordinate, the fractional release. The concentration of SM was 0 (control), $0.34,1.7$, and $8.5 \mathrm{~mm}$ for the filled circles, triangles, squares, and open circles, respectively. The Ca concentration was adjusted to $10 \mathrm{~mm}$. The theoretical dose-release curves of TEA were computed from Eq. (5) with the following parameters: [Ca] $=10 \mathrm{mM}, K_{\mathrm{A}}=0.50 \mathrm{mM}, K_{\mathrm{Ca}}=0.55 \mathrm{mM}, K_{\mathrm{D}}=0.50 \mathrm{mM}, P_{\mathrm{A}}=0.90, P_{\mathrm{Ca}}=$ 0.15 , and $\alpha=8.0$. The vertical bar indicates S.E. The data are averages on 27 (control), 23 (0.34 mM SM), 23 (1.7 mM SM), and 17 (8.5 mM SM) muscles. 

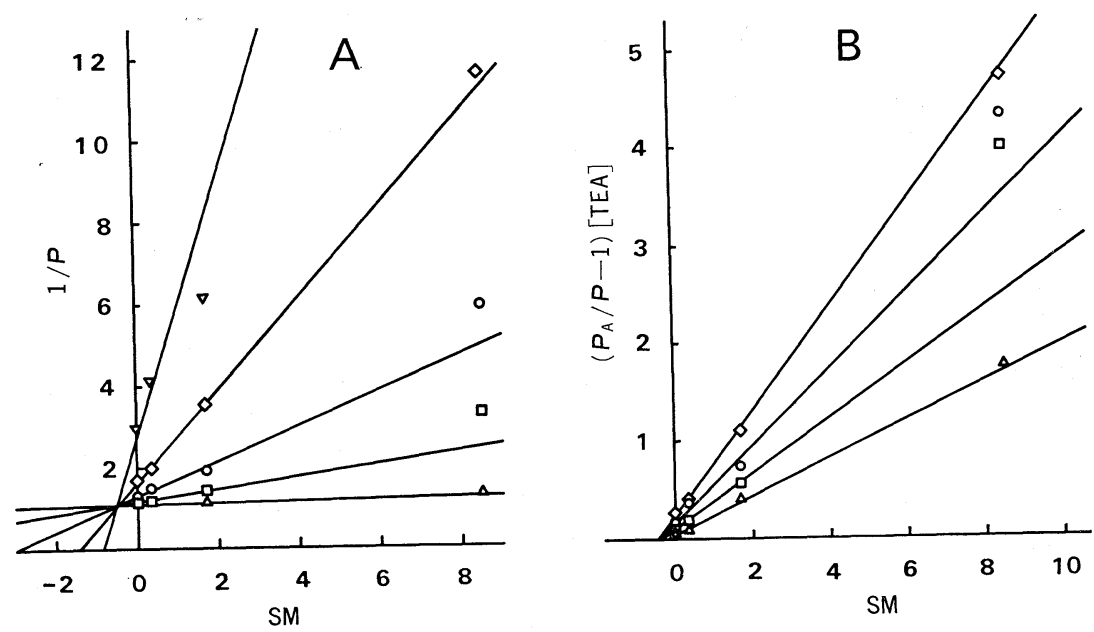

Fig. 6. A: Dixon plot of the data shown in Fig. 5. Abscissa, the concentration of SM in $\mathrm{mm}$; ordinate, the reciprocal of the fractional release. The concentration of TEA was $0.2,0.5,1,2$, and $10 \mathrm{~mm}$ for the inverted triangles, diamonds, circles, squares, and triangles, respectively. The straight lines were derived from Eq. (6) using the fixed parameters shown below; $[\mathrm{Ca}]=10 \mathrm{mM}, K_{\mathrm{A}}=0.50 \mathrm{mM}, K_{\mathrm{Ca}}=0.55 \mathrm{mM}, K_{\mathrm{D}}=0.50 \mathrm{mM}$, $P_{\mathrm{A}}=0.90, P_{\mathrm{Ca}}=0.15$, and $\alpha=10$. Note that the coordinates of the crossing point of the fitted lines for the two extreme concentrations of TEA (e.g., two lines fitted for triangles and inverted triangles) is approximately equal to $[\mathrm{D}]=-K_{\mathrm{D}}$ and $1 / P=1 / P_{\mathrm{A}}$. $\mathrm{B}: \mathrm{A}$ linear relation found between $\left(P_{\mathrm{A}} / P-1\right)$ [TEA] (ordinate in $\mathrm{mM}$ ) and [D] (abscissa in $\mathrm{mm})$. The diamonds, circles, squares, and triangles represent the data obtained in 0.5 , 1, 2, and $5 \mathrm{~mm}$ TEA Ringer, respectively. The straight lines were drawn from Eq. (7) by adopting the following parameters; $[\mathrm{Ca}]=10 \mathrm{mM}, K_{\mathrm{A}}=0.48 \mathrm{mM}, K_{\mathrm{Ca}}=0.50 \mathrm{mM}, K_{\mathrm{D}}=$ $0.50 \mathrm{mM}, P_{\mathrm{A}}=0.90, P_{\mathrm{Ca}}=0.15$, and $\alpha=8.0$.

\section{Effects of $C a$ ions and $S M$ on the ehnanced evoked release with TEA}

TEA restores the neuromuscular transmission of botulinum toxin (BoTx)poisoned preparations to almost normal levels. The TEA effect in antagonizing BoTx action is greater at higher Ca concentrations (LUNDH et al., 1977). Similarly in the present experiments, $\mathrm{Ca}$ ions were found to act synergistically with TEA. An increase in the external Ca concentration shifted the dose-release curve of TEA towards the left (Fig. 3). The values of $K_{\mathrm{A}}, K_{\mathrm{Ca}}, P_{\mathrm{A}}$, and $P_{\mathrm{Ca}}$ used for the calculation from Eq. (5) of fitted theoretical curves were $0.50 \mathrm{~mm}, 0.55 \mathrm{~mm}, 0.90$, and 0.15 , respectively. If a bimolecular reaction really underlies the facilitatory action of TEA, then Eq. $\left(7^{\prime}\right)$ described in DISCUSSION predicts the presence of a linear $P /\left(P_{\mathrm{A}}-P\right)$ [TEA] versus [TEA] relation, the slope of which is a function of the $\mathrm{Ca}$ concentration. This could be confirmed in the present experiment as presented in Fig. 4B. The value of $K_{\mathrm{A}}$ determined from the point of convergence on $X$-axis of the extrapolated lines was $0.50 \mathrm{~mm}$ (see Discussion for details), which was close to $0.40-0.52 \mathrm{~mm}$ reported for $\mathrm{K}$ channel blockade in the node of Ranvier (HILLE, 
1967; Mozhayeva and Naumov, 1972). $\quad K_{\mathrm{Ca}}, P_{\mathrm{Ca}}$, and $P_{\mathrm{A}}$ were estimated to be $0.50 \mathrm{~mm}, 0.15$, and 0.90 , respectively. The parameters for $\mathrm{Ca}$ ions were almost identical with those adopted in the previous paper (MAENo et al., 1981).

We have shown in the previous paper (MAENO et al., 1981) that SM antagonized in a competitive manner the increase in evoked release caused by 4AP. Similarly, SM was found in the present experiments to suppress competitively the enhanced evoked release with TEA. SM shifted the dose-release curve of TEA to the right without altering the value of $P_{\mathrm{A}}$ (Fig. 5). A replot of the data of Fig. 5 shows that the relation between the concentration of SM and the reciprocal of $P$ was linear (Fig. 6A), as was the case with 4AP. The values of the dissociation constant of SM $\left(K_{\mathrm{D}}\right)$ and the parameter for the enhanced evoked release $\left(P_{\mathrm{A}}\right)$ graphically estimated from this Dixon plot were $0.50 \mathrm{mM}$ and 0.90 , respectively. The former value of $0.50 \mathrm{~mm}$ is identical with that obtained with 4AP experiments (MAENo et al., 1981). Figure 6B shows a linear relation between $\left(P_{\mathrm{A}} / P-1\right)[\mathrm{TEA}]$ and the concentration of SM anticipated from Eq. (7) described in Discussion.

\section{The fractional release measured on TTX-treated muscle}

Since the wave form of the spike potential in the nerve terminal has a tendency to change during a train of stimuli in high TEA Ringer (MAENo et al., 1982), it is possible that this introduces certain errors in the measurement of $P$. Therefore, there might be some question regarding the validity of the present experimental procedures. Though not decisive, we tried to answer this question by

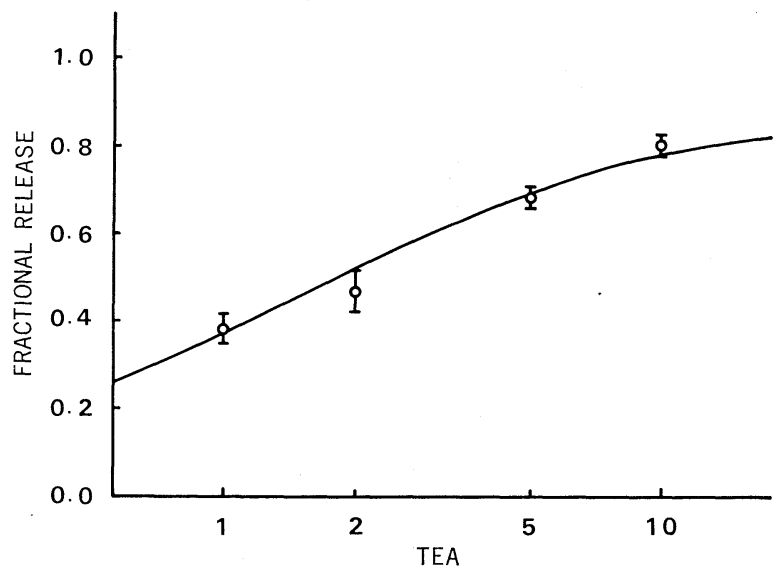

Fig. 7. Dose-release curve of TEA obtained from TTX-treated preparation. Abscissa, the concentration of TEA in $\mathrm{mM}$ on a logarithmic scale; ordinate, the fractional release. Averages on 7-8 endplates in 6-8 muscles. Fitted curve was calculated from monomolecular kinetics of the accelerator as proposed in the previous paper (MAENo et al., 1981) using the following parameters ([Ca] $=0.9 \mathrm{mM},[\mathrm{D}]=0 \mathrm{mM}, K_{\mathrm{A}}=0.26 \mathrm{mM}, K_{\mathrm{Ca}}=$ $0.50 \mathrm{~mm}, P_{\mathrm{A}}=0.90$, and $P_{\mathrm{Ca}}=0.15$ ). The vetrical bar shows S.E. 
measuring $P$ s from the EPPs in TTX-treated muscle. It is highly probable that in the presence of TTX focal depolarization of the nerve terminal region eliminated the errors of presynaptic origin in TEA-Ringer (alteration in the wave form of action potentials in a train, long-lasting repetitive firing etc.). As presented in Fig. 7, the value of $P_{\mathrm{A}}$ in TTX-treated muscle (0.90) was identical with that of untreated muscle. This implied that a tremendous increase in the value of $P$ in high TEA-Ringer might not be an artifact resulting from inconstancy in the wave form of the action potential. However, the dose-release relation of TEA in the presence of TTX seemed to fit better with the first order dose-release curve proposed in the previous paper (MAENo et al., 1981).

\section{DISCUSSION}

Working hypothesis for the action of TEA. In the previous paper (MAENO et al., 1981), the profound facilitatory action of 4AP and the antagonistic effect of SM thereupon were explained by assuming a Ca-sensitive release component $\mathrm{X}$, which has a binding site for release modulators such as 4AP and SM in addition to the well-known capability to react with four Ca ions (DODGE and RAHAMIMOFF, 1967). Customarily, $X$ has been treated as a single entity since it still remains in the state of black box. Under normal conditions the fractional release as well as the number of $\mathrm{ACh}$ quanta released by a single nerve action potential (normal evoked release) is related to the amount of $\mathrm{Ca}_{4} \mathrm{X}$ complex. The combination with $\mathrm{Ca}_{4} \mathrm{X}$ of accelerator (A) represented by $4 \mathrm{AP}$, which is termed in the sense that it accelerates the rate of early tetanic rundown, modifies allosterically the characteristics of $\mathrm{Ca}_{4} \mathrm{X}$ complex resulting in a profound augmentation of the evoked release (accelerated or enhanced evoked release). On the other hand, the combination with $\mathrm{Ca}_{4} \mathrm{X}$ of depressor (D) such as SM depresses transmitter release. In the presence of release modulators, the fractional release $(P)$ calculated from the early tetanic rundown of EPP elicited with the short train stimuli should be related to the sum of the above two forms of release (i.e., normal and enhanced evoked releases).

The slope of the $\log \left\{P /\left(P_{\mathrm{A}}-P\right)\right\}$ versus $\log [\mathrm{TEA}]$ relation in the presence and absence of SM was not unity but close to two (1.7: see Fig. 4A). Also, in the absence of depressor, a linear relationship exists between $P /\left(P_{\mathrm{A}}-P\right)[$ TEA] and [TEA] (Fig. 4B). These suggest that two molecules of TEA are required for the enhancement of the transmitter release. To explain the above TEA effect on the transmitter release, we would like to propose the following scheme:

(1) The release component $X$ has two receptive sites for TEA. By combining with the first specific TEA site of $\mathrm{Ca}_{4} \mathrm{X}$ complex, TEA enhances the transmitter release; the release parameter of $\mathrm{Ca}_{4} \mathrm{X}$ is increased from $P_{\mathrm{Ca}}$ to $P_{\mathrm{A}}$. The dissociation constant of TEA is termed $K_{\mathrm{A}}$. On the other hand, the second nonspecific site of $\mathrm{Ca}_{4} \mathrm{X}$ complex normally reacts only with depressors such as 
SM. Combination of SM with the second site in Ca-bound X completely nullifies the transmitter release.

(2) An analysis of the present data suggests that occupation of the first specific site by a TEA molecule enhances the transmitter release and simultaneously modifies characteristics of the second nonspecific site in the $\mathrm{Ca}_{4} \mathrm{X}$ complex in two ways; the reaction of SM with the second site is suppressed by a factor of $\alpha$ (i.e., the dissociation constant of SM is increased from $K_{\mathrm{D}}$ to $\alpha K_{\mathrm{D}}$ ) and TEA becomes capable of competing with SM for the occupancy of this site. To simplify the mathematical treatment, we assume that the dissociation constant of the nonspecific site for TEA is also $K_{\mathrm{A}}$ and that TEA in combination with the nonspecific site does not affect the action of TEA at the specific site.

Thus, the present hypothesis assumes the presence of two forms of enhanced evoked release with TEA in addition to normal release and two forms of depression with SM (note that D denotes SM in the following equations).

$$
\begin{aligned}
& 4 \mathrm{Ca}+\mathrm{X} \stackrel{K_{\mathrm{Ca}}}{\rightleftharpoons} \mathrm{Ca}_{4} \mathrm{X} \stackrel{P_{\mathrm{Ca}}}{\rightleftharpoons} \text { normal evoked release. } \\
& \mathrm{TEA}+\mathrm{Ca}_{4} \mathrm{X} \stackrel{K_{\mathrm{A}}}{\rightleftharpoons} \mathrm{TEA} \cdot \mathrm{Ca}_{4} \mathrm{X} \stackrel{P_{\mathrm{A}}}{\rightleftharpoons} \text { enhanced evoked release. } \\
& \mathrm{TEA}+\mathrm{TEA} \cdot \mathrm{Ca}_{4} \mathrm{X} \stackrel{K_{\mathrm{A}}}{\rightleftharpoons} \mathrm{TEA}_{2} \cdot \mathrm{Ca}_{4} \mathrm{X} \stackrel{P_{\mathrm{A}}}{\rightleftharpoons} \text { enhanced evoked release. } \\
& \mathrm{D}+\mathrm{Ca}_{4} \mathrm{X} \stackrel{K_{\mathrm{D}}}{\rightleftharpoons} \mathrm{D} \cdot \mathrm{Ca}_{4} \mathrm{X} \longrightarrow \text { no evoked release. } \\
& \mathrm{D}+\mathrm{TEA} \cdot \mathrm{Ca} \mathrm{X}_{2} \stackrel{\alpha K_{\mathrm{D}}}{\rightleftharpoons} \mathrm{TEA} \cdot \mathrm{D} \cdot \mathrm{Ca}_{4} \mathrm{X} \longrightarrow \text { no evoked release. }
\end{aligned}
$$

Consequently, the fractional release in the presence of both TEA and SM was calculated from the following equations;

$$
\begin{gathered}
P=P_{\mathrm{Ca}}\left[\mathrm{Ca}_{4} \mathrm{X}\right] /[\mathrm{X}]_{\mathrm{T}}+P_{\mathrm{A}}\left(\left[\mathrm{TEA} \cdot \mathrm{Ca}_{4} \mathrm{X}\right]+\left[\mathrm{TEA}_{2} \cdot \mathrm{Ca}_{4} \mathrm{X}\right]\right) /[\mathrm{X}]_{\mathrm{T}} . \\
P=\frac{P_{\mathrm{Ca}}+P_{\mathrm{A}}\left(1+\frac{[\mathrm{TEA}]}{K_{\mathrm{A}}}\right) \frac{[\mathrm{TEA}]}{K_{\mathrm{A}}}}{\left(1+\frac{K_{\mathrm{Ca}}}{[\mathrm{Ca}]}\right)^{4}+\left(1+\frac{[\mathrm{TEA}]}{K_{\mathrm{A}}}\right) \frac{[\mathrm{TEA}]}{K_{\mathrm{A}}}+\left(1+\frac{[\mathrm{TEA}]}{\alpha K_{\mathrm{A}}}\right) \frac{[\mathrm{D}]}{K_{\mathrm{D}}}} .
\end{gathered}
$$

Adopting the following fixed parameters $\left(K_{\mathrm{A}}=0.50 \mathrm{mM}, K_{\mathrm{Ca}}=0.55 \mathrm{mM}, K_{\mathrm{D}}=\right.$ $0.50 \mathrm{mM}, P_{\mathrm{A}}=0.90, P_{\mathrm{Ca}}=0.15$, and $\alpha=8.0$ ), the curves shown in Figs. 3 and 5 were computed from Eq. (5), which fitted the data reasonably well.

Modification of the above Eq. (5) yields a linear $1 / P$ versus [D] relationship (Dixon plot); i.e.,

$$
\frac{1}{P}=\frac{\left(1+\frac{K_{\mathrm{Ca}}}{[\mathrm{Ca}]}\right)^{4}+\left(1+\frac{[\mathrm{TEA}]}{K_{\mathrm{A}}}\right) \frac{[\mathrm{TEA}]}{K_{\mathrm{A}}}+\left(1+\frac{[\mathrm{TEA}]}{\alpha K_{\mathrm{A}}}\right) \frac{[\mathrm{D}]}{K_{\mathrm{D}}}}{P_{\mathrm{Ca}}+P_{\mathrm{A}}\left(1+\frac{[\mathrm{TEA}]}{K_{\mathrm{A}}}\right) \frac{[\mathrm{TEA}]}{K_{\mathrm{A}}}} .
$$


In the case of $P=P_{\mathrm{A}}$, the above equation can be reduced to

$$
[\mathrm{D}]=-\frac{K_{\mathrm{D}}\left\{\left(1+\frac{K_{\mathrm{Ca}}}{[\mathrm{Ca}]}\right)^{4}-\frac{P_{\mathrm{Ca}}}{P_{\mathrm{A}}}\right\}}{1+\frac{[\mathrm{TEA}]}{\alpha K_{\mathrm{A}}}} .
$$

Since $\left\{\left(1+K_{\mathrm{Ca}} /[\mathrm{Ca}]\right)^{4}-P_{\mathrm{Ca}} / P_{\mathrm{A}}\right\}$ is almost unity in $10 \mathrm{~mm}$ Ca-Ringer, we obtain $[\mathrm{D}]=-K_{\mathrm{D}}$ when $[\mathrm{TEA}] \ll K_{\mathrm{A}}$, and $[\mathrm{D}]=0$ when $[\mathrm{TEA}] \gg K_{\mathrm{A}}$. Thus, unlike the case of 4AP (MAENO et al., 1981), all the linear regression lines in Fig. 6A never cross a single point where the coordinates are $1 / P_{\mathrm{A}}$ and $-K_{\mathrm{D}}$. However, using the experimental data with two extreme concentrations of TEA, we were still able to determine graphically the approximate values of $K_{\mathrm{D}}$ and $P_{\mathrm{A}}$ from the Dixon plot. The straight lines in Fig. 6A were calculated from Eq. (6) with the following fixed parameters; $K_{\mathrm{A}}=0.50 \mathrm{mM}, K_{\mathrm{Ca}}=0.55 \mathrm{mM}, K_{\mathrm{D}}=0.50 \mathrm{mM}, P_{\mathrm{A}}=$ $0.90, P_{\mathrm{Ca}}=0.15$, and $\alpha=10$.

When $P$ is large (e.g., [TEA] $>0.5 \mathrm{~mm})$ Eq. (6) can be rewritten in approximation

$$
\left(\frac{P_{\mathrm{A}}}{P}-1\right)[\mathrm{TEA}]=\frac{K_{\mathrm{A}}{ }^{2}\left\{\left(1+\frac{K_{\mathrm{Ca}}}{[\mathrm{Ca}]}\right)^{4}-\frac{P_{\mathrm{Ca}}}{P_{\mathrm{A}}}+\left(1+\frac{[\mathrm{TEA}]}{\alpha K_{\mathrm{A}}}\right) \frac{[\mathrm{D}]}{K_{\mathrm{D}}}\right\}}{K_{\mathrm{A}}+[\mathrm{TEA}]} .
$$

Consequently, we can expect a linear relationship between $\left(P_{\mathrm{A}} / P-1\right)[\mathrm{TEA}]$ and [D], the slope of which depends on [TEA]. The extrapolation of this linear relation intersects the $X$-axis at the point predicted by Eq. $\left(6^{\prime}\right)$. Thus, if [TEA] is much smaller than $K_{\mathrm{A}}$, we find in approximation $[\mathrm{D}]=-K_{\mathrm{D}}$. The straight lines in Fig. $6 \mathrm{~B}$ were obtained from Eq. (7) with the following fixed parameters; $[\mathrm{Ca}]=$ $10 \mathrm{mM}, K_{\mathrm{A}}=0.48 \mathrm{mM}, K_{\mathrm{Ca}}=0.50 \mathrm{mM}, K_{\mathrm{D}}=0.50 \mathrm{mM}, P_{\mathrm{A}}=0.90, P_{\mathrm{Ca}}=0.15$, and $\alpha=8.0$.

In the absence of depressor, inversion of Eq. (7) yields a linear relation between $P /\left(P_{\mathrm{A}}-P\right)[\mathrm{TEA}]$ and $[\mathrm{TEA}]$; i.e.,

$$
\frac{P}{\left(P_{\mathrm{A}}-P\right)[\mathrm{TEA}]}=\frac{K_{\mathrm{A}}+[\mathrm{TEA}]}{K_{\mathrm{A}}{ }^{2}\left\{\left(1+\frac{K_{\mathrm{Ca}}}{[\mathrm{Ca}]}\right)^{4}-\frac{P_{\mathrm{Ca}}}{P_{\mathrm{A}}}\right\}} .
$$

The slope of this linear $P /\left(P_{\mathrm{A}}-P\right)[\mathrm{TEA}]$ versus [TEA] relation is a function of [Ca], and the extrapolated straight lines converge to a single point on the $X$-axis where $[\mathrm{TEA}]=-K_{\mathrm{A}}$, as presented in Fig. $4 \mathrm{~B}$. The fitted lines in this figure were calculated from Eq. $\left(7^{\prime}\right)$ using the following fixed parameters; $K_{\mathrm{A}}=0.50 \mathrm{mM}$, $K_{\mathrm{Ca}}=0.50 \mathrm{mM}, P_{\mathrm{A}}=0.90$, and $P_{\mathrm{Ca}}=0.15$.

Factors affecting the accuracy of the present measurements of $P$. The remarkable postsynaptic action of TEA is well known (KoKETSU, 1958; PARSONS, 1969; AdLER et al., 1979; KATZ and MILEDI, 1979). TEA depresses the amplitude of endplate currents (EPCs) in a voltage-dependent manner. Thus ADLER et al. 
(1979) reported that in the presence of $0.25 \mathrm{~mm}$ or more TEA, the linear relationship between peak EPC amplitude and membrane potential becomes markedly nonlinear until it exhibits negative conductance in the hyperpolarized region. Since the enhanced evoked release could be observed only with higher doses of TEA, the strikingly nonlinear current-voltage relationship of EPC mentioned above would inevitably result in an overestimation of $P$. In contrast, 4AP has been shown not to have any postsynaptic actions (Molgó et al., 1977; LUNDH, 1978).

The constancy of the wave-form of the propagated terminal action potential or of the $\mathrm{Ca}$ influx associated with it is an a priori assumption of the present TEA experiments. In the presence of $2 \mathrm{~mm}$ or more TEA, we noted that the waveform of the focally recorded terminal action potentials was apt to vary during successive nerve stimuli (MAENo et al., 1982). However, since the extracellularly recorded terminal action potential is the time derivative of the intracellular potential change, one cannot distinguish between a reduction in the action potential amplitude and a slowing in the potential change. Although these would possibly introduce a certain error while determining $P$ s in high concentrations of TEA, an agreement of the present values of $P_{\mathrm{A}}$ in TEA-Ringer between TTX-treated and untreated muscles suggests that this error might not be too great.

However, the finding that the kinetics of the action of TEA on $P$ seem to turn to a first order process in TTX-treated muscle is a puzzle. This might be interpreted to mean that one of the two TEA sites postulated in the present paper is related to a TTX-sensitive excitatory process in the presynaptic membrane. Alternatively, it might be thought that bimolecular characteristics of TEA action is a resultant of an overestimation of $P$ in high TEA Ringer. Focal depolarization of the nerve terminal region in TTX-treated preparations would eliminate potential sources of overestimation of $P$ such as alteration in the wave-form of action potentials in a train and long-lasting repetitive firing. It might be interesting to note in this connection that several investigators have suggested the presence of two distinct receptive sites for TEA or its derivatives in the frog sciatic nerve (Armstrong and Hille, 1972; CurTis and Scurlock, 1981).

Comparison with previously reported data. The present data suggest that TEA modifies transmitter release through the combination of TEA with Cabound release component $\mathrm{X}$ in a bimolecular fashion. This finding is not new. For instance, a replot of the data of LUNDH et al. (1977) shows that the enhancing effect of TEA on the indirectly elicited twitch response in BoTx-treated muscle is also mediated via a bimolecular reaction of TEA; the Hill coefficient is found to be about 2.0 for TEA whereas that for 4AP is roughly 1.2. Volle and BRANISTEANU (1976) reported that the coefficient of the power relation between the mean quantal content of EPP $(m)$ and TEA below $0.1 \mathrm{~mm}$ is 0.81 . Nevertheless, this does not conflict with the present hypothesis. It is apparent that when [TEA] is smaller than $K_{\mathrm{A}}$ Eq. (5) can be reduced to a first order equation in [TEA]. 
Thus, the linear $\log \left\{P /\left(P_{\mathrm{A}}-P\right)\right\}$ versus $\log [\mathrm{TEA}]$ plot should level off below $[\mathrm{TEA}]=K_{\mathrm{A}}$. In fact, the apparent Hill coefficient changes from 1.72 to 0.91 in the vicinity of $[$ TEA] $=0.33 \mathrm{~mm}$, as presented by broken lines in Fig. $4 \mathrm{~A}$.

The total store of available ACh quanta $(N)$ would presumably represent the total population of vesicles (about 35,000) deployed along about 700 active zones in the nerve terminal (KATZ and MiLEDI, 1979). According to their data the number of $\mathrm{ACh}$ quanta released with a single terminal depolarization $(m)$ in the presence of $10-20 \mathrm{mM}$ TEA and $0.5 \mu \mathrm{g} / \mathrm{ml}$ TTX is about $31,000-80,000$. Since $P=m / N, P$ was calculated to be $0.89-1.00$. This is almost identical to the present value of $P_{\mathrm{A}}(0.90)$ measured on TTX-treated and -untreated preparations. Similarly, ILLES and THESLEFF (1978) reported that the EPP amplitude of TTXtreated muscle was depressed rapidly by repetitive nerve stimulation of $5 \mathrm{~Hz}$ after the application of $6 \mathrm{~mm}$ TEA. The value of $P$ estimated from the ratio between the fifth and first EPPs with their data was 0.59 (Ca concentration, $1.8 \mathrm{~mm}$ ). This is close to the present value of $P$ obtained under similar conditions $(P=0.69$ : $5 \mathrm{~mm}$ TEA and $0.9 \mathrm{~mm} \mathrm{Ca}$ ).

On the other hand, a synergistic interaction on twitch augmentation between TEA and 3,4-diaminopyridine (34DAP) has been described (HARVEY and MARSHALL, 1977). However, since such a synergism between TEA and 34DAP was also seen in directly stimulated preparations, this could be ascribed in part to combined effects of the two chemicals on the contractile mechanism. Similarly, LUNDH et al. (1977) reported that when the maximal effect on the BoTxtreated endplates was produced by $0.13 \mathrm{~mm} 4 \mathrm{AP}$, the $\mathrm{ACh}$ release was increased still further by the additions of $1.6 \mathrm{~mm}$ TEA. From the differences in the time courses of the drug actions, they suggested that 4AP has an intracellular site of action whereas TEA acts extracellularly. It might be interesting to note that a difference in the kinetics of action between 4AP and TEA was also noted by studying the $\mathrm{pH}$ dependence of the two drugs (Molgó et al., 1980). These imply that TEA and aminopyridines possess different binding capacities for two different sites or processes in the complex chain of events of depolarization-secretion coupling. Though we have no supporting data at the present stage, one possibility is that TEA exerts an additional action through combination with the site specific for TEA in the release component $\mathrm{X}$.

The authors express their thanks to Dr. C. Edwards for reading the manuscript. The present investigation was supported in part by the Grant-in-Aid for Scientific Research from the Ministry of Education, Science and Culture of Japan (557035).

\section{REFERENCES}

Adler, M., Oliveira, A. C., Albuquerque, E. X., Mansour, N. A., and Eldefrawi, A. T. (1979) Reaction of tetraethylammonium with open and closed conformations of the acetylcholine receptor ionic channel complex. J. Gen. Physiol., 74: 129-152.

Armstrong, C. M. and Hille, B. (1972) The inner quaternary ammonium ion receptor in 
potassium channels of the node of Ranvier. J. Gen. Physiol., 59: 388-400.

COLLIER, B. and EXLEY, K. A. (1963) Mechanism of the antagonism by tetraethylammonium of neuromuscular block due to $d$-tubocurarine or calcium deficiency. Nature, 199: 702-703.

Curtis, B. M. and Scurlock, J. E. (1981) The mechanism of action of local anesthesia by tetraethylammonium derivatives. Anesthesiology, 54: 260-277.

Dodge, F. A. and RAHAMimofF, R. (1967) Co-operative action of calcium ions in transmitter release at the neuromuscular junction. J. Physiol. (Lond.), 193: 419-432.

Harvey, A. L. and Marshall, I. G. (1977) The facilitatory actions of aminopyridines and tetraethylammonium on neuromuscular transmission and muscle contractility in avian muscle. Naunyn Schmiedebergs Arch. Pharmacol., 299: 53-60.

Hille, B. (1967) The selective inhibition of delayed potassium currents in nerve by tetraethylammonium ion. J. Gen. Physiol., 50: 1287-1302.

Illes, P. and ThesLeFF, S. (1978) 4-Aminopyridine and evoked transmitter release from motor nerve endings. Br. J. Pharmacol., 64: 623-629.

KATZ, B. and Miledi, R. (1979) Estimates of quantal content during 'chemical potentiation' of transmitter release. Proc. R. Soc. Lond. (Biol.), 205: 369-378.

KoKeTsu, K. (1958) Action of tetraethylammonium chloride on neuromuscular transmission in frogs. Am. J. Physiol., 193: 213-218.

Kusano, K., Livengood, D. R., and Werman, R. (1967) Tetraethylammonium ions: Effect of presynaptic injection on synaptic transmission. Science, 155: 1257-1259.

Llinás, R., Steinberg, I. Z., and Walton, K. (1976) Presynaptic calcium current and their relation to synaptic transmission: Voltage clamp study in squid giant synapse and theoretical model for the calcium gate. Proc. Natl. Acad. Sci. U.S.A., 73: 2918-2922.

Llinás, R., Steinberg, I. Z., and Walton, K. (1981) Relationship between presynaptic calcium current and postsynaptic potential in squid giant synapse. Biophys. J., 33: 323-351.

LuNDH, H. (1978) Effects of 4-aminopyridine on neuromuscular transmission. Brain Res., 153: 307-318.

Lundh, H., Leander, S., and Thesleff, S. (1977) Antagonism of the paralysis produced by botulinum toxin in the rat: The effects of tetraethylammonium, guanidine and 4-aminopyridine. J. Neurol. Sci., 32: 29-43.

Maeno, T., Enomoto, K., and Ichinose, M. (1982) Modes of action on the neuromuscular transmission of various chemical release modulators. Proc. Jpn. Acad., 58B: 69-72.

Maeno, T., Enomoto, K., and Sawada, M. (1981) Kinetic analysis of the action of chemical modulators on neuromuscular transmission. Jpn. J. Physiol., 31: 639-656.

Molgó, J., Lemeignan, M., and Lechat, P. (1977) Effect of 4-aminopyridine at the frog neuromuscular junction. J. Pharmacol. Exp. Ther., 203: 653-663.

Molgó, J., LundH, H., and TheslefF, S. (1980) Potency of 3, 4-diaminopyridine and 4-aminopyridine on mammalian neuromuscular transmission and the effect of pH changes. Eur. $J$. Pharmacol., 61: 25-34.

Mozhayeva, G. N. and Naumov, A. P. (1972) Tetraethylammonium ion inhibition of potassium conductance of the nodal membrane. Biochim. Biophys. Acta, 290: 248-255.

Otsuka, M., Endo, M., and Nonomura, Y. (1962) Presynaptic nature of neuromuscular depression. Jpn. J. Physiol., 12: 573-584.

Parsons, R. L. (1969) Mechanism of neuromuscular blockade by tetraethylammonium. Am. J. Physiol., 216: 925-931.

Stovner, J. (1958) The anticurare activity of tetraethylammonium (TEA). Acta Pharmacol. Toxicol. (Copenh.), 14: 317-332.

TAkeUChI, A. (1958) The long-lasting depression in neuromuscular transmission of frog. Jpn. J. Physiol., 8: 102-113.

Volie, R. L. and Branisteanu, D. D. (1976) Statistical parameters of transmitter release at frog neuromuscular junctions treated with guanidine or tetraethylammonium. J. Pharmacol. Exp. Ther., 197: 653-661. 